http://dx.doi.org/10.30681/23588403v12i01121134

\title{
EXU: O RASTRO DE UMA ESCRITURA EM CONSTANTE ADIAMENTO
}

\section{Data de recebimento:21/05/2019}

Aceite: 30/06/2019

\section{Joémerson de Oliviera SALES (SEDUC/MT) ${ }^{1}$} Rosana Arruda de SOUZA (UFMT) ${ }^{2}$

Resumo: Nossa proposta de trabalho é discutir a figura de Exu utilizando algumas noções derridianas como o rastro e a escritura. Este orixá africano tem sua figura apresentada sempre sob duas vertentes uma positiva e uma negativa, mas consegue migrar entre elas, utilizando o próprio impasse de não significar, nem uma nem outra coisa unicamente, como meio de manter-se, tal como o rastro e a escritura, uma potência de significação.

Palavras-chave: Exu, rastro, escritura.

Abstract: Our proposal of work is to discuss the figure of Exu using some derridian notions like the trace and the writing. This african orixá has its figure always presented in two ways a positive and a negative, but it manages to migrate between them, using the own impasse of not to signify, neither one thing nor another, like means of itself maintaining, as the trace and the writing, a potency of signification.

Keywords: Exu, trace, writing.

\section{Introdução}

Jacques Derrida afirma que a literatura é uma não unidade, pois não há uma essência do literário. Nessa linha de pensamento, o autor ainda considera que a literatura se marca como uma instituição que tudo diz e que tudo pode dizer. Em outras palavras, a partir de sua capacidade de ficção a ela cabe a liberdade de trazer à tona qualquer coisa.

Em seu dizer aberto, e em constante devir, temas, assuntos, conceitos são tecidos numa rede que ora se confunde com a vida. Para Italo Calvino (2015), a escrita se dá para que o mundo não escrito se afiance, então, em seus fios são entremeados a vida.

Ruth Silviano Brandão também compreende a literatura como "uma especial dimensão da vida” (BRANDÃO, 2006, p. 11). E de seu espaço outros espaços surgem, deslocam-se, são adiados, são almejados. Este movimento é o que dá força à escritura, que se caracteriza como

\footnotetext{
${ }^{1}$ Licenciado em Letras com habilitação em Língua Portuguesa e suas respectivas literaturas pela UFMT/CUR e mestre em Estudos de Linguagem com ênfase em Estudos Literários pela Universidade Federal de Mato Grosso (UFMT), professor de Língua Portuguesa na escola Plena Pindorama de Rondonópolis - SEDUC-MT.

${ }^{2}$ Licenciada em Letras com habilitação em Língua Portuguesa e suas respectivas Literaturas pela UFMT/CUR e mestre em Estudos de Linguagem com ênfase em Estudos Literários pela Universidade Federal de Mato Grosso (UFMT). Em doutoramento em Estudos de Linguagem pela Universidade Federal de Mato Grosso (UFMT). Bolsista Capes/Fapemat.
} 


\section{Revista de Estudos Acadêmicos de Letras}

"a consciência de que a palavra falta, de que há uma falha na linguagem que, paradoxalmente, realiza-se na escrita que nasce de um não-saber e da recusa de saberes feitos" (BRANDÃO, 2006, p.111).

Em virtude disso, pensar a representação de Exu - orixá africano - leva-nos a ideia de rastro proposta por Jacques Derrida, uma vez que Exu é visto de uma forma fragmentada e sua significação, em nossa cultura, é negociada a partir de seu pólo negativo, numa tentativa de aplicar a Exu o status do mal empreendido pelo logos cristão.

Em detrimento dessas leituras pejorativas da representação de Exu, nossa reflexão mobiliza outro olhar "desse personagem" a partir das Lendas de Exu (2011), escritas pelo autor Adilson Martins. Em nossa investigação pretendemos observar como Exu é apresentado nas lendas e a partir das faces apontadas pelos textos buscamos relacionar seu adiamento de sentido como uma forma de enfraquecer sua complexidade em nossa cultura.

\section{As lendas e seu autor}

Lendas de Exu é uma obra escrita por Adilson Martins que, conforme o próprio autor, figura um dos três livros que mais gostou de produzir, junto de O papagaio que não gostava de mentiras e outras fábulas africanas (2008) e Erinlé o caçador e outros contos africanos (2010). O autor nasceu em 23 de setembro de 1940, no Rio de Janeiro.

Sua produção se destaca por trazer à tona questões da cultura africana e concomitantemente afro-brasileira. Nos contos e nas fábulas, visualizamos alguns personagens que também se fazem presentes nas lendas, como o elefante e o sapo. A escritura de Martins se faz por meio da explicação e da leveza de seu vocabulário muito próximo às vezes da oralidade, que ajuda o leitor a emergir no universo místico dos orixás.

Nas lendas, Exu é apresentado por seu caráter volátil, em quarenta e quatro narrativas. Ora a personagem se mostra compadecida pelos problemas humanos, ora, sentindo-se afrontada por não receber seu ebó, castiga aquele que não fez a devida oferenda. E assim se constrói a figura de Exu. Suas faces são apresentadas sob várias perspectivas e em cada uma delas se é possível observar sua diferença.

Selecionamos de As lendas de Exu quatro narrativas para serem analisadas: Os cabelos brancos, $\mathrm{O}$ sapo e o hipopótamo, $\mathrm{O}$ barco e o cais e $\mathrm{O}$ escravo lançado às águas. 


\section{Exu sob um olhar derridiano}

Exu está presente nos espaços espíritas protagonizando diversos rituais, realizados com maior frequência em locais fronteiriços, como a encruzilhada. A ele são feitas oferendas, como bebida, fumo e farofas, tidas como material de força espiritual e, por outro lado, o estopim de diversas interpretações que nascem no imaginário popular a respeito do caráter ambíguo, entre maldade e bondade, que impera sobre a divindade. Exu não se apresenta como bom nem mau: ele tem o poder de reinar na fronteira dos sentimentos e, por isso, supera interpretações e expectativas, pois destoa da máscara de bondade e equilíbrio que geralmente atribuímos aos deuses.

Longe, no entanto, de fazermos julgamentos a respeito de posições religiosas, procuramos, aqui, colocar Exu no âmbito da escrita, ou melhor, da escritura (aos modos de Derrida) e averiguar como o entorno da figura se constrói por meio de inúmeras máscaras de significantes.

O pensamento de Derrida tem sido utilizado para embasar, muito além de discussões no campo linguístico, discussões de ordem humana e social, isso porque o filósofo, em Gramatologia (2013[1967]), volta-se contra o que ele chama de metafísica do logos e da phoné, ou seja, uma era de conhecimentos até então centrados na fala, tida por elemento sempre superior à escrita e lócus supremo de toda forma de conhecimento.

Nessa esteira, podemos considerar um logocentrismo e um fonocentrismo que abrem caminho a um etnocentrismo, visto que a quem pode falar (e ser ouvido) se atribui o conhecimento e o poder. Assim, a fala permaneceu durante muito tempo assentada no tropo da presença, ao passo que à escrita atribuía-se o lugar do silêncio, como mero suplemento e imagem da fala:

[...] o privilégio da phoné não depende de uma escolha que teria sido possível evitar. Responde a um momento de economia (digamos, da "vida" da "história" ou do "ser como relação a si"). O sistema do "ouvir-se-falar" através da substância fônica - que se dá como significante não-exterior, nãomundano, portanto não-empírico ou não-contingente - até mesmo produziu a ideia de mundo, a ideia do mundo a partir da diferença entre o mundano e o não mundano, o fora e dentro, a idealidade e não-idealidade, o universal e o não-universal, o transcendental e o empírico (DERRIDA, 2013, p. 09).

Assim o sistema da phoné produzia dualidades lógicas e limitadoras do tipo o bem/o mal, e se fazia, certo modo, função limitadora da própria vida: aquilo que não se dobrava à voz e ao conhecimento ficava num "fora" da linguagem. O que Derrida fez foi refutar (sem 


\section{Revista de Estudos Acadêmicos de Letras}

anular) a lógica de Saussure a respeito do significante/significado ou escrita/fala. O próprio Saussure chegou a promulgar a supremacia da fala ao declarar que "o objeto linguístico não se define pela combinação da palavra escrita e da palavra falada; esta última por si só constitui tal objeto" (1970 apud DERRIDA, 2013, p. 37).

Dentro desta linha de raciocínio, propomos utilizar o pensamento de Derrida como ferramenta para trazer à luz elementos que durante muito tempo permaneceram neste local de "fora" da linguagem, fora da conjuntura de poder onde impetram aqueles que podem falar e ser ouvidos. Neste espaço de abstração e silêncio, muitos elementos humanos e sociais aparecem alocados, mas elegemos aqui a figura de Exu que ocupa o entremeio de ausência e presença. Relegamo-lo ao silêncio, mas parece que é deste silêncio que emana seu poder, sendo que Exu fica camuflado nas mais diversas relações humanas, movendo-as como peças de xadrez.

Como exemplo do que foi apontado até aqui, analisamos a lenda Os cabelos brancos. Resumidamente, temos um narrador em terceira pessoa que situa a história contada em "naquele tempo [em que] os homens não reconheciam a liderança entre eles mesmos" (MARTINS, 2011, p. 114). Exu foi chamado para orientar a eleição de um homem que liderasse os demais. "Depois de muito discutirem, os membros da assembleia resolveram que o comando de seus destinos deveria ser confiado ao mais velho entre eles e, como não sabiam contar o tempo, seria escolhido aquele que possuísse os cabelos mais encanecidos" (MARTINS, 2011, p. 115).

Exu desaprovou a decisão. Para ele, a velhice não é sinônimo de sabedoria, pois os “canalhas também envelhecem"(MARTINS, 2011, p. 115). Aproveitando o momento em que todos estavam acomodados numa sala, fez sacudir as palhas que a cobria e delas caiu pó de efun que fez todos ficarem com os cabelos brancos. Sendo assim, eles tiveram que estabelecer outro critério. Muitas propostas foram levantadas, até que um ancião careca propôs que o mais sábio entre todos é quem deveria ser eleito. No final da história, a este mesmo autor da proposta foi confiada a liderança dos homens, pois apenas um sábio pensaria semelhante alternativa.

Na história, percebemos que Exu não aparece diretamente. Sua voz não é escutada, senão através das escolhas feitas pelos homens que agem (sem saber) sob o domínio de suas artimanhas. Ardilosamente, ele modifica um logos há muito assentado: o de que a sabedoria sempre correspondia à velhice dos homens. Nos últimos parágrafos, uma espécie de moral é pregada confirmando o que foi dito no meio da história e afirmando o poder do próprio Exu: 
E foi assim que Exu, na primeira eleição do mundo, evitou que se elegesse alguém que, embora muito velho, não fosse capaz de governar com sabedoria.

Aprendemos, assim, que os velhos, embora dignos de todo respeito, nem sempre são totalmente confiáveis ou competentes para emitir conceitos e orientar nossas vidas (MARTIS, 2011, p. 116).

Numa ótica derrediana, a escritura ${ }^{3}$ pode, ironicamente, ser vista como algo maléfico por constituir uma série de acidentes que afetam a linguagem ao longo da história. Ou seja, o fato de ela ter sido relegada à exterioridade do sistema linguístico pode atender ao sentimento de temeridade que ela causa. O silêncio da escritura ameaça os conhecimentos préestabelecidos e subverte o que até então se tinha como equilibrado. Assim, podemos considerar que Exu age no campo da escritura, e não no da fala. Ele é a ferramenta muda com a qual se articula toda a assembleia contada na história. Nesta, a solução se apresenta com a voz do ancião careca autor da ideia sábia. Mas isso só se deu depois do silêncio (Exu) preparar toda a situação.

Entretanto, Exu nem sempre se faz inaudito. Ele deixa ouvirem sua voz, mas nessa autorização, comanda sua autoridade de entidade traiçoeira e de juiz cruel.

Na lenda $O$ sapo e o hipopótamo, Exu é chamado para resolver o impasse entre o sapo e o hipopótamo. O impasse, na realidade, era mais do sapo, pois este ecoava aos quatro cantos sua insatisfação ao ver o hipopótamo na posição de rei do lago. Para ele, não cabia que um ser pudesse ser rei apenas pelo critério do tamanho (de fato o hipopótamo era o maior animal dali), outros critérios tinham de ser levados em conta: "se fôssemos adotar um critério justo, haveríamos de coroar um rei não pela avaliação de seu tamanho, mas sim por sua inteligência e versatilidade e, com toda a certeza, uma vez utilizados estes critérios, seria eu o coroado!" (MARTINS, 2011, p. 104).

Os bichos resolveram em assembleia que o árbitro da decisão que nomearia o novo rei seria Exu. No dia da decisão, cada candidato expôs seus argumentos, o primeiro foi o hipopótamo:

- Acho que sou mais indicado para ocupar o cargo porque sou pacífico, mas, se for necessário, poderei manter a ordem, fazendo valer a minha força e o meu tamanho. Não acredito que exista aqui qualquer um que possa desafiar-

\footnotetext{
${ }^{3}$ Derrida usa o termo escritura, em vez de escrita, remetendo não apenas à grafia, mas a tudo que conduz uma rede de significantes. Nesse sentido, a própria fala passa a ser significante a despeito de ser a origem e significado de tudo como antes se enunciava. Saussure argumentou que aprendemos a falar antes de aprender a escrever, mas temos que lembrar que antes da fala já há significantes, afinal, o bebê já não se faz entender sem sons, sem choro? Antes da fala, de fato, não houve escrita, mas a escritura, sim, desde sempre.
} 
me para uma luta corporal! Sempre mantive a paz no lago e, até hoje, não precisei apelar para a violência e, por este motivo, devo continuar a reinar sobre meus vizinhos (MARTINS, 2011, p. 105).

Quando chegou a vez do sapo:

de há muito, venho tentando mostrar a todos o quanto de inútil tem sido o hipopótamo como rei de nosso lago. O que tem feito em benefício de nossa comunidade? Nada! [...]

Tudo o que esta montanha de carne sabe fazer é cochilar e, vez por outra, bocejar, escancarando a enorme bocarra, o que, sem dúvida, não só assusta, como representa um grande risco para os pequeninos animais.

Precisamos de alguém que reine com inteligência e sabedoria e este alguém sou eu, o sapo!

Não pensem senhores que não sou capaz de manter a paz, se necessário for, usando a força! Quero revelar a todos, neste momento, um segredo que guardo há muito tempo, por pura humildade. Se quiser, e quando quiser, posso aumentar meu tamanho, ficando maior e mais forte do que meu opositor! (MARTINS, 2011, p. 105-106).

Diante da revelação, Exu deu por encerrada a eleição e concederia ao sapo a coroa. Disse que o sapo tinha feito um belíssimo discurso, provado sua inteligência e que só faltava demonstrar a todos o que dissera, sobre sua capacidade de aumentar de tamanho. Envaidecido, o sapo inspirou o ar o quanto pôde e, a pedido de Exu, o fez mais uma vez e mais vezes. Exu sempre dizia que ainda faltava para ficar do tamanho do hipopótamo, até que, na última vez que inspirou o ar, o sapo tanto se inflou que explodiu:

chocados com o que viram, os animais aclamaram o hipopótamo seu legítimo rei e compreenderam que cada um nasce com o seu próprio destino e deve conformar-se com suas limitações.

E é desta forma que Exu castiga aqueles que querem ser o que não podem. Força-os a inflar-se com o ar da vaidade, até que explodam e morram sem conseguir realizar seus delírios de grandeza (MARTINS, 2011, p. 107).

Nesta lenda, diferentemente da anterior, Exu fala diretamente aos demais personagens da história. Por outro lado, podemos também entender que ele continua a agir sob o silêncio: primeiro, porque ele aparece sem alguma distinção ontológica, seu nome é evocado na história, mas não é informado quem ele é, se um animal como os outros, um ser propriamente físico ou, de fato, uma entidade a quem os bichos dizem ouvir; segundo, porque toda a sua articulação na eleição do rei se mostra artificiosa, é como se ele fizesse justiça por meio da enganação. 
O sapo é seduzido por Exu a se inflar e inflar e, assim, no final, corou-se o hipopótamo, aquele que ao contrário do sapo, não tentou ser quem não era. Porém, para haver este acontecimento de justiça, o sapo foi eliminado. Poderíamos nos questionar se a justiça não poderia ter sido feita sem que se chegasse a este extremo. Por que Exu não parou de insistir que o sapo se inflasse desde a primeira vez, em que já se observou a mentira do anfíbio a respeito de poder se tornar maior tanto quanto o hipopótamo?

Na lenda em análise, observa-se uma explicação ao trabalho de apartamento voltado a Exu, em função do temor a este que causa transformações silenciosas por caminhos traiçoeiros e duvidosos. Exu age na lenda como a escritura, que vem para construir o justo desconstruindo as dicotomias estabelecidas, no caso, e a maior delas, a do bem e do mal.

Um dos maiores movimentos conduzidos por Derrida decorre do que ele chama de desconstrução. É preciso desconstruir o logos como figura plena e criadora, ele se mostra na fala, que nada tem de criadora, porque é apenas máscara daquilo que sempre permanecerá no devir. Para Georgia Amitrano, a desconstrução é um termo derridiano proposto para

um processo de análise crítico-filosófica que tem por objetivo imediato a crítica da metafísica ocidental e da sua tendência para o logocentrismo, incluindo a crítica de certos conceitos (o significado e o significante; o sensível e o inteligível; a origem do ser; a presença do centro; o logos, etc.) que tal tradição havia imposto como estáveis. A desconstrução não é um método, o "método desconstrutivo" como é comum se dizer. Também não pode ser compreendida como uma teoria previamente construída sobre o ser, as coisas em geral, o homem, a razão, a história etc. Um "pensamento da desconstrução" nada está subordinado a uma teoria prévia. Trata-se, antes, de um trabalho de pensamento que procura investigar os limites de toda teorização e, portanto, de toda pretensão de totalização que se encontra operante em um discurso. O próprio Derrida afirma que a desconstrução consiste em um pensamento sempre comprometido em pensar a origem e os limites da questão “o que é?” (2015, p. 620-621).

A figura de Exu percorre o caminho da desconstrução, porque ele foi situado ao longo dos tempos exatamente no caminho da desfaçatez para encobrir sua presença e, ao mesmo tempo, coibir este próprio processo realizado para encobri-lo, então, ele se construiu por meio de sua própria desconstrução.

Conforme Reginaldo Prandi (2001, p. 51), quando a religião dos orixás, originalmente politeísta, veio a ser praticada no Brasil do século XIX por negros que eram ao mesmo tempo católicos, todo o sistema cristão de pensar o mundo em termos do bem e do mal deu um novo formato à religião africana, no qual um novo papel esperava por Exu, uma vez que a 


\section{Revista de Estudos Acadêmicos de Letras}

concepção dualista bem/mal é judaico-cristã e não existia na África. Exu foi colocado no lado do mal como uma maneira de ajustar a religião dos orixás ao modelo cristão, continua o autor.

Assim, Exu foi trasvestido pela figura do mal apenas para atender à dicotomia cristã. No entanto, conforme ressalta Prandi (2001), não há quem reconheça que recorra à entidade para fazer o mal. Interpreta-se o mal apenas como decorrência da própria prática do bem, em contraversão ao logos cristão de que o bem só pode levar a ele mesmo.

$\mathrm{Na}$ visão desconstrucionista de quem recorre a Exu, pois, podemos assumir que não houve maldade alguma em Exu de quando impulsionou o sapo a demonstrar seu poder de tornar-se maior. A ação de Exu tinha o intuito de praticar o bem, enquanto o sapo desencadeou o infortúnio da situação. Repetimos a fala inicial do sapo: "se fôssemos adotar um critério justo, haveríamos de coroar um rei não pela avaliação de seu tamanho, mas sim por sua inteligência e versatilidade". No entanto, quando teve a vez de argumentar, o anfíbio corrompeu seu discurso e não fez outra coisa que tentar ser coroado pela avaliação de seu próprio tamanho.

Entretanto, como advoga Prandi (2001), Exu é aquele que rompe a tradição sendo o próprio princípio do movimento, porque rompe limites e contraria as normas que regulam o cotidiano, neste caso, fica aberta a análise da figura de Exu e sua articulação ao longo da lenda: podemos (numa atitude de autocontradição) desvirtuar o seu gesto e dizer (com apego à visão de escritura) que Exu teve, sim, o intuito de praticar o mal, e o bem foi só a decorrência da prática do mal.

Seguindo nosso trajeto de análise, destacamos mais duas lendas que nos permitem indagar as faces de Exu. A saber: $O$ barco e o cais e $O$ escravo lançado às águas. Percebemos no decorrer da leitura que Exu se molda pela ação de seus interlocutores. Sua natureza benfeitora/impiedosa depende da realização do ebó. Esta oferenda caracteriza a noção de dever ponderada por Derrida em sua obra Paixões. Para ele,

trata-se do conceito de dever, e de saber se, ou até que ponto, pode-se confiar nele, naquilo que ele estrutura na ordem da cultura, da moral, da política, do direito, até da economia (sobretudo quanto à realização entre a dívida e o dever); quer dizer, se e até que ponto pode-se confiar naquilo que o conceito de dever ordena em todo discurso responsável sobre a decisão responsável, em todo discurso, toda lógica, toda retórica $d a$ responsabilidade. Ao falar de discurso responsável sobre a responsabilidade, já implicamos que o próprio discurso deve se submeter às normas ou à lei da qual fala. Essa implicação parece inelutável, mas continua desconcertante: qual poderia ser a responsabilidade, a qualidade ou a virtude da responsabilidade nunca poderia ser assumida sem equívoco e sem contradição? que a autojustificativa de uma decisão é impossível e não poderia, a priori e por razões estruturais, de maneira alguma responder por si própria? (DERRIDA, 1993, p. 16). 


\section{Revista de Estudos Acadêmicos de Letras}

$\mathrm{Na}$ esteira do pensamento derridiano sobre o dever, vislumbramos o ato da realização/não realização do ebó como decorrente do discurso de Exu. Sua atuação centra-se numa responsabilidade, pois a ele se confere o gesto de "julgar, cobrar, avaliar e, por fim, conceder a última palavra de ordem”. Dessa maneira, sua presença é marcada por sua ausência, já que apenas a sua voz se faz ecoar aludindo o que deve ser feito para evitar que algum mau presságio ocorra ou para articular a condenação do transgressor.

Na lenda $O$ barco e o cais, temos a "disputa por prestígio e importância” (MARTINS, 2011, p. 42) encenada pelo barco e o cais. A narrativa segue com a convocação de Exu, que intima a ambos a realizarem um ebó "composto inteiramente de peixes e frutos do mar" (MARTINS, 2011, p. 43). Depois de sete dias Exu retornou para declarar quem seria o vencedor da disputa, no entanto apenas o cais havia realizado a oferenda.

O barco em contrapartida opôs-se alegando:

- Se Exu quer comer peixes, que os compre no mercado ou vá pescar. Sei muito bem qual de nós dois é o melhor e não preciso oferecer sacrifícios para que meu valor seja reconhecido por todos!

$\mathrm{E}$ assim pensando, continuou indolente, a balançar-se ao sabor das pequenas ondas (MARTINS, 2011, p. 43).

Exu quando descobre que o barco se nega a realizar a oferenda incumbida, fica furioso e para se vingar e dar uma lição no rebelde dirigiu-se até Olokun:

- Agô, Olokun! - exclamou Exu entrando no palácio de Olokun, o rei dos mares.

- Ajuba, Exu! - respondeu o Orixá com cordialidade. - A que devo tão agradável visita?

- Venho matar saudade do amigo e, aproveitando o ensejo, fazer uma denúncia de alguém que vive em teu reino o que, sem dúvida, faz dele um súdito teu!

[...]

- Trata-se de um tal de barco, invenção homem. Começou sua carreira humildemente mas agora, ninguém saber por quê, ficou tão vaidoso que se autodenomina rei dos mares - envenenou Exu.

- Mas como rei dos mares? Só existe um rei dos mares coroado por Olodumare, e este sou eu! - bradou indignado Olokun, cuja ira era fácil de ser despertada.

$[\ldots]$

- Eu te agradeço pela informação, Exu. Vou tratar, hoje mesmo, deste tal barco! - vociferou o rei, já encrespado de raiva (MARTINS, 2011, p. 44).

O mesmo fez com Iansã, envenenando-a contra o barco, acusando-o de usurpador: 
- O tal barco possui um pedaço de lona, a que chama de vela, que, segundo ele mesmo afirma, tem o poder de aprisionar o vento, fazendo-o trabalhar como um escravo que o leva para onde pretenda ir! Por este motivo, vive declarando a todo mundo que reina sobre o vento!

Mal disfarçando sua fúria, Oyá resmungou entre os dentes:

- Ah! Quer dizer, então, que o tal de barco acha que domina e reina sobre o vento? ...E com uma simples vela de lona? Veremos que poder é esse! disse a Senhora dos raios, das tempestades e dos ventos (MARTINS, 2011, p. 45).

Ludibriados pelas mentiras contadas por Exu, Olokun e Iansã agiram impiedosamente contra o barco e dele apenas restaram:

[...] destroços, pedaços de madeira, de cordas e de lona, que flutuavam ao sabor das ondas, que, aplacadas, acariciavam, agora, as paredes do cais.

$\mathrm{O}$ cais, porque fizera o ebó, permaneceu intacto, como se nada tivesse acontecido, mas o barco... pobre barco...dele nada sobrou, a não ser a lembrança de sua vaidade gravada num pedaço de madeira abandonada à deriva, onde se podia ler: Rei dos Mares (MARTINS, 2011, p. 46).

Tornando ao pensamento de dever, o barco tem sua irreverência castigada. E dessa forma o discurso de Exu torna-se uma resposta implacável à falta cometida pelo barco. O ebó configura-se como suplemento da escritura realizada por Exu. Em outras palavras, a personagem é movida pelos sacrifícios que marcam a sua presença. Portanto, se pensarmos no logos cristão que atende à premissa do bem como caminho inadiável podemos aqui reler Exu como uma contrapartida disso.

Sua aparição na lenda é dada pela necessidade de julgamento. Logo após, avaliado a intriga entre o barco e o cais, a personagem oferece-lhes uma determinação para se chegar a uma conclusão. Mas ao se passar os dias dados para a realização da oferenda Exu se aborrece, pois apenas o cais cumpre com o estabelecido. É nessa altura, nessa quebra de protocolo, que Exu se faz presente e providencia o castigo ao barco.

Na lenda $O$ escravo lançado às águas, temos um jovem que está "cansado de sua sina" (MARTINS, 2011, p. 90) e por isso resolve "consultar Ifá e na consulta lhe foram dadas ordens para fazer um ebó em honra de Exu. Só assim a sua sorte poderia mudar” (MARTINS, 2011, p. 90). Então rapidamente o mancebo se apruma para realizar o que lhe fora peço, pois não aguenta mais as humilhações e os trabalhos pesados aos quais era submetido.

Desse modo, o ebó é realizado e no ato de sua realização o jovem é surpreendido pelo seu senhor que: 
[...] conduziu-o, aos pontapés, de volta para a fazenda.

Lá chegando, o homem levou o escravo até a beira do rio onde havia, já há muito tempo, uma grande caixa de madeira muito bem vedada.

Obrigando o infeliz a entrar na caixa, pregou a tampa e, em seguida, lançoua às águas revoltas (MARTINS, 2011, p. 91).

Logo após, a sua desdita, a caixa encalha numa praia onde seu rei havia falecido e para encontrar uma solução: "os adivinhos reais consultaram o oráculo para saber quem iria ocupar o trono, já que o falecido não havia deixado herdeiros" (MARTINS, 2011, p. 91). E a mensagem, que também vinha de Exu, era a de que: "aquele que surgir das águas deverá ser coroado, para que reine sobre vós, com justiça e sabedoria!" (MARTINS, 2011, p. 91).

A mensagem de Exu a primeiro momento pareceu pouco clara para os adivinhos reais que intimaram que fizessem busca ao homem nascido das águas. E nisso os pescadores se encontraram com a misteriosa caixa e pensaram que ali se achava grande tesouro e a surpresa aconteceu quando encontraram um homem amarrado. Diante desse impasse procuraram o rei, sem saber de seu falecimento.

Nesta lenda, seguimos ainda sob a lógica do dever, entretanto percebemos que nessa narrativa evidencia-se a problemática da responsabilidade. De acordo com Derrida,

Problema também diz, em certos contextos, as desculpas apresentadas para se esquivar ou se desculpar, mas ainda uma outra coisa que aqui talvez nos interessasse mais: por metonímia, por assim dizer, problema pode vir a designar aquele que, como diz em francês, dá cobertura, endossando a responsabilidade de um outro ou se fazendo passar pelo outro, falando em nome do outro, aquele que se coloca à frente ou atrás de quem alguém se dissimula. [...] Desse ponto de vista, a responsabilidade seria problemática à medida suplementar que poderia ser às vezes, talvez mesmo sempre, aquele que se assume não por si, em seu próprio nome e frente ao outro (a mais clássica definição metafísica da responsabilidade), mas aquela que se deve assumir por um outro, no lugar, em nome do outro, e um outro do outro, a saber, o inegável mesmo da ética. "À medida suplementar", dizíamos, mas devemos ir mais longe: à medida que a responsabilidade não apenas diminui, mas, pelo contrário, surge numa estrutura que também é suplementar (DERRIDA, 1993, p. 17-18).

Diferentemente da última lenda, nesta a personagem recorre a Exu para mudar a sua sorte, aceitando assim cumprir com a realização do ebó. O que difere é que no ato de sua devoção o jovem é pego no momento em que está prestando o sacrifício e seu dono ao saber do motivo ironiza-o e castiga-o. Nesse momento podemos ver a responsabilidade do discurso, ou, melhor, sua problemática.

A voz de Exu é sempre figurativa de sua presença. E para o jovem que queria livrar-se das péssimas condições em que era submetido confiar em Exu era seu único auspício. No 


\section{Revista de Estudos Acadêmicos de Letras}

entanto, a princípio ele acaba em uma situação pior e desconhecendo os propósitos de Exu termina preso e acorrentado numa caixa que é lançada às águas.

Se parássemos a narrativa aí, teríamos em xeque o dever. Como mesmo indaga Derrida, pois: "qual a responsabilidade, a qualidade ou a virtude da responsabilidade, de um discurso consequente que pretendesse demonstrar que uma responsabilidade nunca poderia ser assumida sem equívoco e sem contradição?” (DERRIDA, 1993, p. 16). Nesse sentido, a responsabilidade de Exu resvalaria no equívoco e na contradição, porém como o ebó caracteriza sua lógica suplementar e temos aqui a ação benfeitora de Exu, o jovem tem sua sorte realmente mudada.

A lenda termina com uma grande festa: "para comemorar a coroação e, desta forma, o ex-escravo pôde ver, como dissera seu malvado amo, o quanto sua sorte pôde melhorar por haver cultuado Exu" (MARTINS, 2011, p. 92). Notamos que o impasse, ou, nos termos derridianos, a problemática é o fator que determina a presença de Exu. Assim, com a necessidade de seu julgamento ou intervenção, vem a exigência do ebó. Este representa a medida suplementar que proporciona a capacidade de Exu de tomar sua responsabilidade, providenciando, então, a solução ou castigo.

O que podemos analisar é que a ação de Exu não se assenta no maniqueísmo produzido pelo logos cristão. Sua ação é demandada de acordo com a "interpretação" de seus interlocutores. Isso significa que o ebó também é pura escritura, pois transmite uma recusa a um destino traçado. Sua ação é sempre na intenção de mudar. Desse modo, Exu fala por meio de outro nome, assume uma responsabilidade que também é suplementar na medida em que esta está condicionada à falta humana.

A intervenção de Exu caracteriza a produção de um discurso que nem sempre é claro como vimos nesta última lenda. A fala a primeiro momento não se faz compreensiva, só depois que os pescadores chegam com o escravo é que se elucida a questão. Logo podemos dizer que aí a escritura não é apenas a trapaça da língua, mas é a deriva em que se permite ouvir sob outra instância aquilo que está traçado.

\section{Considerações finais}

Exu, nas lendas de Adilson Martins, representa em partes aquilo que foi conceituado de seu ser: o vilão, o cruel e o zombeteiro. Mas também extrapola as derivas do significado, 
desdobrando assim a dicotomia "significante/significado", fazendo ouvir a sua voz em campos não marcados pelo logos cristão.

Desta forma, Exu traz à tona o que Roland Barthes determinou sobre a literatura,

[...] grafo complexo das pegadas de uma prática: a prática de escrever. [...] porque o texto é o próprio aflorar da língua, e porque é no interior da língua que a língua deve ser combatida, desviada: não pela mensagem de que ela é o instrumento, mas pelo jogo de palavras de que ela é o teatro (BARTHES, 1978, 17).

As lendas engendram a resistência de uma escritura que se recusa a saberes feitos, como pensa Brandão; esses saberes são o que se cristalizou em nossa cultura sobre Exu e a partir das narrativas de Adilson Martins somos levados à complexidade desta personagem que se revela, permite-se captar, em seu caráter volátil. Assim, a prática de escritura de Martins nos faz ponderar as pegadas de um discurso de fronteira.

Em melhores palavras, podemos dizer que Exu é ponto de fronteira. Seu rastro é trapaça da língua, pois faz ouvir o poder sob outra instância de sentido, uma vez que "poder é, simetricamente, perpétuo no tempo histórico" (BARTHES, 1978, p. 12). Dito isso, consideramos o ebó enquanto representação tanto da voz e escritura de Exu. Presença e ausência se imiscuem dando origem à salvação ou à punição daqueles que estão diante do julgo de Exu.

Referências:

AMITRANO, Georgia. Com-por, rastros e espectros de Derrida. Educação e Filosofia, Uberlândia, v. 29, n. 58, p. 615-630, jul./dez 2015.

BARTHES, Roland. Aula. São Paulo: Cultrix, 1978.

BRANDÃO, Ruth Silviano. A vida escrita. Rio de Janeiro: 7Letras, 2006.

CALVINO, Italo. Mundo escrito e mundo não escrito - artigos, conferências e entrevistas. São Paulo: Companhia das Letras, 2015.

DERRIDA, Jacques. Gramatologia. 2.ed. São Paulo: Perspectiva, 2013. Paixões. São Paulo: Papirus, 1993. 
PRANDI, Reginaldo. Exu, de mensageiro a diabo. Revista USP, São Paulo, n.50, p. 46-63, junho/agosto 2001.

MARTINS, Adilson. Erinlé, o caçador e outros contos africanos. Ilustrações de Luciana Justiniani Hess. Rio de Janeiro: Pallas, 2010.

Lendas de Exu. 2.ed. Rio de Janeiro: Pallas, 2011.

O papagaio que não gostava de mentiras e outras fábulas africanas. Ilustrações de

Luciana Justiniani Hess. Rio de Janeiro: Pallas, 2008. 